\title{
Role of biochemical markers in testicular cancer: diagnosis, staging, and surveillance
}

\author{
This article was published in the following Dove Press journal: \\ Open Access Journal of Urology \\ 29 December 2011 \\ Number of times this article has been viewed
}

\author{
Jaclyn C Milose \\ Christopher P Filson \\ Alon Z Weizer \\ Khaled S Hafez \\ Jeffrey S Montgomery \\ Department of Urology, University \\ of Michigan, Ann Arbor, MI, USA
}

Correspondence: Jeffrey S Montgomery

I500 East Medical Center Drive,

Ann Arbor, MI 48109, USA

$\mathrm{Tel}+\mathrm{I}(734) 7639269$

Fax +I (734) 9369127

Email montrose@umich.edu

\begin{abstract}
Testis cancer is one of the few solid organ malignancies for which reliable serum tumor markers are available to help guide disease management. Human chorionic gonadotropin, alpha fetoprotein, and lactate dehydrogenase play crucial roles in diagnosis, staging, prognosis, monitoring treatment response, and surveillance of seminomatous and nonseminomatous germ cell tumors. Herein we discuss the clinical applications of germ cell tumor markers, the limitations of these markers in the management of this disease, and additional serum molecules that have been identified with potential roles as novel germ cell tumor markers.
\end{abstract}

Keywords: testicular cancer, tumor markers, bhCG, AFP, surveillance, diagnosis

\section{Introduction}

Due to significant advances in the multimodal treatment of testicular germ cell tumors (GCTs), including improved disease staging techniques, effective platinum-based combination chemotherapy regimens, aggressive surgical resection of residual disease, and a policy of close surveillance after primary therapy, men with testis cancer have some of the highest survival rates ( $>95 \%$ 5-year disease-specific survival) of any solid organ malignancy. ${ }^{1}$ Additionally, the young age and good health of most testicular cancer patients allow them to better tolerate intense chemotherapeutic and surgical treatments, contributing to their favorable outcomes. Central to the success in treating GCTs is the development and widespread use of sensitive and reliable GCT markers.

Testicular cancer represents approximately $1 \%$ of all cancers diagnosed in men, and is the most common solid organ malignancy among men aged 15-35 years. ${ }^{2}$ In 2011, an estimated 8000 incident cases of testicular cancer were diagnosed in the US. ${ }^{3}$ Nearly all testis tumors are GCTs, which are categorized as either seminoma or nonseminoma GCTs (NSGCTs) based on histology. NSCGTs are divided into four subtypes: choriocarcinoma, yolk sac, embryonal, and teratoma. Approximately $60 \%$ of GCTs contain more than one of these histologic patterns (ie, mixed GCTs). ${ }^{4}$ The most frequent combination of tumor types is embryonal, yolk sac, and teratoma. ${ }^{4}$ The pure (ie, nonmixed) GCT types include:

- Seminoma: $30 \%-60 \%$ of GCTs

- Embryonal: 3\%-4\% of GCTs (although embryonal is present in up to $40 \%$ of mixed NSGCTs)

- Teratoma: $5 \%-10 \%$ of GCTs

- Choriocarcinoma: 1\% of GCTs. submit your manuscript $\mid$ www.dovepress.com

Dovepress

http://dx.doi.org/10.2147/OAJU.SI5063
Open Access Journal of Urology 2012:4 I-8

(C) 2012 Milose et al, publisher and licensee Dove Medical Press Ltd. This is an Open Access article which permits unrestricted noncommercial use, provided the original work is properly cited. 
Testicular GCTs are unique in that tumor markers are readily available to guide clinicians in disease management. Despite the extensive evidence regarding the importance of tumor markers in testicular cancer care, there are data indicating that they are underutilized. ${ }^{5}$ This has obvious quality of care implications, as testicular tumor marker levels are important in assigning the appropriate disease stage after orchiectomy, determining patient prognosis, deciding appropriate treatment, monitoring disease response to therapy, and for the early identification of recurrence during post-therapy surveillance. In the following review, we will discuss the role of the commonly available GCT markers in the management of patients with testicular cancer (ie, alpha fetoprotein [AFP], human chorionic gonadotropin [hCG], and lactate dehydrogenase $[\mathrm{LDH}])$. Furthermore, we will highlight recent innovations in the development and implementation of novel testicular tumor markers.

\section{Common testicular cancer tumor markers Alpha fetoprotein}

AFP is a 70 kilodalton single-chain glycoprotein, which in the fetus is synthesized in the yolk sac, liver, and intestine and serves as a major serum binding protein. Peak levels are noted during week 12 to 14 of gestation and then steadily decline so that 1 year after birth, AFP levels should be $<15 \mathrm{ng} / \mathrm{mL}$. With regard to GCTs, AFP is primarily produced by yolk sac (endodermal sinus) components and to a lesser extent by embryonal carcinomas and teratomas. AFP can be found in up to $20 \%-25 \%$ of teratomas and is associated with mucinous glands and hepatoid differentiation. ${ }^{4}$ In one large cohort of nearly 1500 patients with testicular cancer, over $60 \%$ of patients with NSGCTs had elevated AFP levels, making it the most commonly elevated tumor marker in testicular cancer. ${ }^{6}$

Pure choriocarcinoma and pure seminoma do not produce AFP; if AFP is elevated in conjunction with pure forms of these tumors, the specimen should be re-examined for AFP-producing tumor types. ${ }^{7}$ In the case of seminoma, any nonseminomatous elements present dramatically alter the appropriate treatment regimen. If nonseminomatous components cannot be identified histopathologically and these patients have elevated AFP, they should be treated as if they have a NSGCT. The serum half-life of AFP is 5-7 days. GCT levels should normalize after four half-lives, and therefore serum AFP levels should return to normal levels 20-28 days after effective therapy.

\section{Human chorionic gonadotropin}

GCTs produce an intact hCG molecule (a 38 kilodalton protein composed of $\alpha$ and $\beta$ subunits normally secreted by placental syncytiotrophoblasts) and/or the $\beta$ subunit of this protein alone. The $\alpha$ subunit closely resembles that of pituitary hormones, including luteinizing hormone (LH), follicle-stimulating hormone, and thyroid-stimulating hormone. As a result, only the $\beta$ subunit is measured by the most commonly available serum assays. The $\beta$ subunit is a $70 \%$ homolog with LH but has a unique c-terminal extension that allows for differential identification by radioimmunoassay techniques.

The serum half-life of hCG is approximately $24-36$ hours. Normalization of hCG levels after orchiectomy (expected 4-6 days after surgery) for patients with stage I disease indicates likely elimination of the tumor, but persistently elevated levels should raise concern for residual disease. The extent of its elevation depends on histologic tumor subtype and the overall disease burden. With regard to NSGCTs, hCG can be markedly elevated with pure choriocarcinomas but is often only moderately elevated in conjunction with embryonal cell carcinoma and mixed GCTs. Elevations of hCG can also be seen in approximately $10 \%-20 \%$ of patients with stage I seminoma and up to $30 \%-50 \%$ of disseminated seminoma secondary to the presence of syncytiotrophoblastic elements within the tumor, but at serum levels rarely above $500 \mathrm{mIU} / \mathrm{mL}^{7,8}$

\section{Lactate dehydrogenase}

LDH is a 134 kilodalton cellular enzyme produced by muscle (smooth, cardiac, and skeletal), liver, kidney, and brain that catalyzes the interconversion of lactate and pyruvate. LDH has relatively low specificity for GCTs. There are five unique isoforms of LDH, with LDH-1 being the most frequently elevated isoenzyme in testicular cancers. Assays for LDH measure enzymatic activity and not the actual enzyme quantity; therefore, there can be considerable variations in LDH levels dependent on the assay used by a particular laboratory. As a result, elevations of LDH must be taken in the context of other tumor markers and staging studies. LDH is elevated in $40 \%-60 \%$ of men with testicular GCTs. ${ }^{9}$ LDH has limited sensitivity and specificity for seminoma, but LDH levels > $2000 \mathrm{U} / \mathrm{L}$ are more consistent with bulky disease, and rising levels are an accurate indicator of recurrence. ${ }^{10}$ In NSCGTs, LDH is directly related to tumor burden. ${ }^{11}$ An elevated serum LDH level may be the sole biochemical abnormality in $10 \%$ of patients with persistent or recurrent NSGCT. ${ }^{12}$ 


\section{Tumor markers in testicular cancer diagnosis and staging}

Patients with testicular cancer most frequently present with a painless testicular mass. The initial work-up includes a history and physical exam, cross-sectional imaging of the retroperitoneum, chest x-ray, and serum levels of AFP, hCG, and LDH. Table 1 reviews some of the important characteristics of these common testicular tumor markers. Testicular ultrasound is often useful to confirm the diagnosis of an intratesticular mass and eliminate concern for other scrotal pathology. The diagnosis of testicular cancer cannot be made based on elevated tumor markers alone, as these markers lack sufficient sensitivity and specificity. Diagnosis instead relies on the histopathologic examination of the orchiectomy specimen. There are, however, unique clinical scenarios in which patients present with markedly elevated tumor marker levels and symptomatic metastases (eg, extensive lung metastases with resultant dyspnea or bulky retroperitoneal lymphadenopathy with severe pain or edema), and biopsy for tissue diagnosis may not be advisable. In these situations, chemotherapy is often administered prior to orchiectomy based on tumor markers alone so therapy is not delayed as patients recover from surgery. Testicular tumor markers may be the only clue to the tissue of origin if a biopsy of a metastatic site reveals only poorly differentiated carcinoma. These markers are also useful to indicate discrepancies in the pathologic diagnosis of GCTs at the time of orchiectomy, particularly in cases in which elements from the primary tumor have regressed or compose a small fraction of the specimen, limiting identification on histopathologic evaluation.

Serum levels of AFP, hCG, and LDH should be obtained before orchiectomy and repeated weekly thereafter until marker levels normalize. Postorchiectomy tumor marker levels are used for risk stratification and are incorporated into the American Joint Committee on Cancer TNM Staging System for Testis Cancer (Table 2). Men with NSGCTs with persistently elevated hCG or AFP following orchiectomy are presumed to have metastatic disease even without identifiable mass on imaging.

\section{Testicular tumor markers and disease prognosis}

The degree of AFP or hCG elevation is directly proportional to tumor burden, and higher serum levels of these tumor markers have been recognized as poor prognostic indicators. ${ }^{13}$ Therefore, the degree of marker elevation in patients with NSGCTs has been incorporated with staging criteria to
Table I Tumor marker characteristics

\begin{tabular}{lllll}
\hline $\begin{array}{l}\text { Tumor } \\
\text { marker }\end{array}$ & $\begin{array}{l}\text { Size } \\
\text { (daltons) }\end{array}$ & Half-life & $\begin{array}{l}\text { Normal } \\
\text { range }\end{array}$ & Tumor type \\
\hline AFP & 70,000 & $5-7$ days & $<40$ ug/l & $\begin{array}{l}\text { Embryonal, } \\
\text { teratoma, yolk sac }\end{array}$ \\
hCG & 38,000 & $24-36$ hours & $<5 \mathrm{IU} / \mathrm{l}$ & $\begin{array}{l}\text { Seminoma, } \\
\text { choriocarcinoma, } \\
\text { embryonal, }\end{array}$ \\
LDH & 134,000 & Varies & I.5-3.2 ukat/l & Any \\
\hline
\end{tabular}

Abbreviations: AFP, alpha fetoprotein; hCG, human chorionic gonadotropin; $\mathrm{LDH}$, lactate dehydrogenase.

stratify patients into good, intermediate, and poor risk groups according to the International Germ Cell Consensus Classification (Table 3). This stratification predicts prognosis and is used to assign an appropriate chemotherapy course. Bosl et $\mathrm{a}^{14}$ identified elevations of hCG and LDH and the number of metastatic sites as the most significant predictors of survival in patients with GCTs.

Serial measurements of serum tumor markers are used to monitor response to GCT treatment. An appropriate fall in tumor marker levels at a rate consistent with marker half-life indicates adequate disease response. Following radical orchiectomy, failure to normalize serum tumor marker levels suggests metastasis and the need for chemotherapy.

Monitoring these levels in conjunction with radiation or chemotherapy is more complicated, as there is often a more significant time lag between treatment and serum tumor marker normalization. This is secondary to the prolonged and gradual tumor cell death associated with these treatment modalities. Serum tumor markers are typically obtained prior to the initiation of chemotherapy, with subsequent levels obtained on Day 1 of each chemotherapy cycle to monitor the response to therapy. The rate of tumor marker decline during chemotherapy has been proposed as a prognostic indicator in patients with testicular cancer. Those patients whose tumor markers are either slow to decline or do not normalize may have persistently active disease. A retrospective study from the Memorial Sloan Kettering Cancer Center (New York, NY) evaluated 198 patients with GCT treated with chemotherapy. Patients

Table 2 American Joint Committee on Cancer S Stage parameters

\begin{tabular}{llll}
\hline Stage & AFP (ug/l) & hCG (IU/I) & LDH \\
\hline S0 & wnl & wnl & wnl \\
SI & $<1000$ & $<5000$ & $<I .5 \times$ normal \\
S2 & $1000-10,000$ & $5000-50,000$ & $1.5-10 \times$ normal \\
S3 & $>10,000$ & $>50,000$ & $>10 \times$ normal \\
\hline
\end{tabular}

Abbreviations: AFP, alpha fetoprotein; hCG, human chorionic gonadotropin; $\mathrm{LDH}$, lactate dehydrogenase; wnl, within normal limits. 
Table 3 Testicular cancer risk stratification

\begin{tabular}{ll}
\hline Risk status & Nonseminoma \\
\hline Good risk & Postorchiectomy markers - all: AFP $<1000$, \\
& hCG $<5000$, LDH $<1.5 \times$ normal \\
& And \\
& No nonpulmonary visceral metastases \\
& And \\
& Testicular or retroperitoneal primary tumor \\
& Postorchiectomy markers - any: AFP \\
Intermediate risk & I000-10,000, bhCG 5000-50,000, \\
& LDH I.5-10 $\times$ normal \\
& And \\
& No nonpulmonary visceral metastases \\
& And \\
& Testicular or retroperitoneal primary tumor \\
& Postorchiectomy markers - any: AFP $>$ \\
Poor risk & I0,000, hCG $>50,000$, LDH $>10 \times$ normal \\
& Or \\
& Nonpulmonary visceral metastases \\
& Or \\
& Mediastinal primary tumor \\
\hline
\end{tabular}

Abbreviations: AFP, alpha fetoprotein; hCG, human chorionic gonadotropin; $\mathrm{LDH}$, lactate dehydrogenase.

experienced a longer median overall survival when they experienced an appropriate reduction in tumor marker levels (defined by an AFP half-life of less than 7 days and an hCG half-life of less than 3 days). In addition, these patients also had higher rates of complete response than those who did not have expected tumor marker reductions ( $89 \%$ versus $29 \%){ }^{15}$ Recent trials have used prolonged tumor marker decline as an indication for salvage chemotherapy. This innovation resulted in significantly improved overall, disease-specific, and progression-free survival (PFS) among intermediaterisk patients with NSGCTs in one study. ${ }^{16}$ A slower than predicted marker decline during treatment is associated with a higher risk of ultimate treatment failure. In such a situation, there is no need to change chemotherapy or give additional cycles of chemotherapy, but close follow-up is important. ${ }^{9}$

Following an initial course of systemic chemotherapy, the presence or absence of elevated tumor markers in addition to three-dimensional cross-sectional imaging of any known metastatic sites is used to determine whether salvage chemotherapy, surgical intervention with retroperitoneal lymph node dissection and resection of any other metastatic deposits, or observation is indicated. Prior to surgical intervention, though, tumor markers should have normalized or additional chemotherapy or an alternative chemotherapy regimen should be initiated until markers return to normal levels. Exceptions to this are situations in which patients have a growing mass, most commonly teratoma (ie, growing teratoma syndrome), on serial cross-sectional imaging despite chemotherapy, which places patients at considerable risk for added morbidity with further growth. For patients with NSGCTs, it is crucial to resect all residual masses once marker levels have normalized. Historically, surgical resection has been recommended for seminoma patients with bulky disease who undergo chemotherapy and have a residual mass larger than $4 \mathrm{~cm}$ in size. Currently, positron emission tomography scanning is frequently used to evaluate for active disease in these residual masses to determine whether resection is warranted. ${ }^{17}$

\section{Testicular cancer surveillance}

The existence of reliable testicular tumor markers has had a significant impact on testicular cancer surveillance after primary therapy and aids in the early detection of disease recurrence. These markers used in conjunction with periodic imaging are the mainstay of GCT surveillance. The frequency of tumor marker evaluation varies according to the tumor histology, stage, and previous therapy. In a study by Rathmell et al, ${ }^{18}$ elevated AFP and/or hCG was the initial indicator of disease recurrence in $55 \%$ of patients with either NSCGT or seminoma.

hCG, AFP, and LDH should be measured at each surveillance visit in patients with a history of either NSGCT or seminoma, regardless of previous specific tumor marker elevations on initial diagnosis. The pattern of tumor marker elevation at diagnosis does not consistently predict the pattern at recurrence. In a study by Trigo et al, ${ }^{19}$ the records of 794 men treated for testicular cancer were reviewed retrospectively. They found that a tumor marker that was elevated at initial presentation was elevated at the time of first recurrence in $73 \%$ of patients. Those patients who initially presented with negative tumor markers were found to have elevation of at least one marker at the time of initial recurrence $41 \%$ of the time. The identical marker elevation pattern at diagnosis was present at the first recurrence in $78 \%$ of seminomas and $64 \%$ of NSGCTs. At the time of recurrence, elevations of AFP and/or hCG were found in 18 of 44 (41\%) patients with NSGCTs who initially had negative tumor markers. In patients with what was thought to be pure seminoma at the time of diagnosis with negative markers, AFP was elevated at the time of recurrence in four of $24(17 \%)$ patients and hCG in another four of $24(17 \%)$ patients. This group also found that tumor marker elevations tended to be the earliest indicator of disease recurrence in men with NSGCTs (40\%), whereas initial recurrence was most likely found on imaging $(42 \%)$ for men with a history of seminoma. ${ }^{19}$ 
Among patients who experience disease recurrence, the peak levels of serum hCG and AFP at the time of relapse represent one of the three predictors of overall survival (in addition to the length of recurrence-free interval and complete response to initial therapy). Those patients with the highest marker levels at the time of relapse (ie, AFP > $100 \mathrm{kU} / 1$ and/or hCG $>100 \mathrm{IU} / \mathrm{l}$ ) had the poorest outcomes. ${ }^{20}$ Furthermore, Mego et $\mathrm{al}^{21}$ found that the time to normalization of AFP and/or hCG after salvage chemotherapy is an independent predictor of overall and disease-specific survival. They stratified their cohort of patients into four groups: (1) normal markers at baseline and after one cycle of chemotherapy, (2) elevated markers at baseline and normal markers after one cycle, (3) elevated markers at baseline and after one cycle of chemotherapy but with expected time to normalization, and (4) elevated markers at baseline and after one cycle of chemotherapy with a slower than expected rate of decline. The authors categorized patients into two groups: (1)-(3) as having a favorable response and (4) as unfavorable. A variety of salvage regimens were used, with the majority receiving etoposide/ifosfamide/cisplatin (24\%) or paclitaxel/ifosfamide/cisplatin (41\%). Among this cohort, $50 \%$ and $55 \%$ of patients had an unfavorable decline of hCG and AFP, respectively, after one cycle (3 weeks) of chemotherapy. Overall, $34 \%$ of patients achieved a durable response (measured as a 5-year PFS) to salvage chemotherapy. When stratified by tumor marker decline, patients with favorable kinetics had a 58\% 5-year PFS, compared with a 7\% 5-year PFS among patients with unfavorable kinetics $(P<0.001) .{ }^{21}$ This suggests that the rate of marker decline may be useful in predicting a patient's response to salvage chemotherapy.

Approximately $10 \%-30 \%$ of patients with GCT will have a recurrence after initial treatment. Most patients who relapse do so within the first 2 years after primary therapy. ${ }^{22}$ However, approximately $3 \%$ of patients will experience a late relapse (LR), defined as a disease recurrence more than 2 years after a complete response (CR), with no evidence of a second primary neoplasm. ${ }^{23}$ Recurrences have been reported more than 30 years after an initial CR..$^{22}$ Shahidi et $\mathrm{al}^{24}$ reviewed cases of 1263 men with testicular GCTs. Of those men, 255 (20\%) had documented recurrences and 53 (4\%) (15 seminoma; 38 NSGCT) had recurrence more than 2 years after initial presentation. Very late recurrence ( $>5$ years) occurred mainly in patients with a history of metastatic NSGCT, with a $1 \%$ annual risk of recurrence between 5 years and 10 years after primary treatment. A multivariable analysis of the risk of LR in patients with either NSGCT or seminoma identified elevated markers at presentation and the presence of differentiated teratomas in postchemotherapy surgical specimens as significant predictors of recurrence. Elevated markers identified $53 \%$ of the recurrences after 5 years. In this series, only elevated AFP levels at time of late recurrence were observed. ${ }^{24}$ With these findings in mind, it is recommended that surveillance should continue for at least 10 years after primary therapy for GCTs.

In a study of 91 men with histologically documented LRs of testicular GCT, teratoma was the most common tumor type identified (60\%), but this was frequently associated with other tumor types. Yolk sac tumor was the second most common tumor type identified (46\%). Only small numbers of LRs consisted of other tumor types, including non-GCTs, seminoma, embryonal, and choriocarcinoma. ${ }^{23}$ Those patients whose LR consisted of teratoma only had the most favorable outcomes, with 79\% having no evidence of disease (NED) at last follow-up, in contrast to those patients with LRs consisting of nongerm cell malignant tumors or pure GCTs, with only $36 \%$ and $37 \%$ alive with NED, respectively. ${ }^{23}$ Historically, patients with LRs tend to have a poor prognosis, with long-term disease-free survival rates of $26 \%$ and $36 \%$ reported. ${ }^{22,25}$

\section{Current tumor marker limitations}

Although crucial in the management of men with testicular cancer, current serum tumor markers do lack sensitivity and specificity. There are numerous other conditions that can result in elevations in these markers (Table 4). Hypogonadism causes a compensatory increase in the pituitary production of hCG and LH, both of which interact with immunoassays and cause false-positive results. Although marijuana use has been linked to elevations of hCG, this has not been borne out in larger GCT series. ${ }^{26}$ False-positive elevations of hCG have been linked with heterophile antibodies as well. ${ }^{27}$ In addition, hereditary elevations of serum AFP have been described, with affected men having mildly elevated AFP levels in the range of $15-30 \mathrm{ng} / \mathrm{mL}$ at baseline. ${ }^{8,28}$ This condition should be considered only after other common causes of elevated AFP (ie, GCTs, hepatocellular carcinoma) have been excluded. Conversely, a lack of elevated tumor markers during post-therapy surveillance or tumor marker normalization after primary therapy does not ensure that a patient is disease free. Among NSGCT patients who undergo systemic chemotherapy followed by retroperitoneal lymph node dissection, a significant proportion harbor viable tumor and/or teratoma on final pathology despite normalization of preoperative tumor marker levels. In one study of 78 patients with NSGCT treated with chemotherapy followed by surgical 
Table 4 Other conditions with elevations in tumor markers

\begin{tabular}{lll}
\hline AFP & hCG & LDH \\
\hline Hepatocellular carcinoma & Hydatidiform mole & Skeletal muscle disease \\
Viral hepatitis & Hypogonadism & Pulmonary embolism \\
Hereditary tyrosinemia & Breast cancer & Myocardial infarction \\
Ataxia-teleangiectasia & Gonadotroph adenomas \\
Cirrhosis & Bladder, liver, pancreas, stomach, lung, kidney cancer \\
Gastric, biliary, and pancreatic cancer & Heterophile antibodies \\
Bronchial cancer & \\
Antiepileptics and anesthetics & \\
Hereditary persistence of AFP & \\
\hline
\end{tabular}

Abbreviations: AFP, alpha fetoprotein; hCG, human chorionic gonadotropin; LDH, lactate dehydrogenase.

resection of residual masses, $28 \%$ were found to have mature teratoma and $6 \%$ had immature teratoma on pathology. ${ }^{29}$

\section{Other germ cell tumor markers}

Given the limitations of the available tumor markers for testicular cancer, research has been targeted on identifying superior markers. The ideal GCT marker would have high sensitivity and specificity. Its serum levels would correlate with disease burden, respond to therapy in a reliable manner, and be elevated in seminoma and NSGCT alike or would exhibit exquisite specificity for either seminoma or NSGCT. Being able to more completely differentiate between these two tumor types would have significant treatment implications. Several potential alternative GCT markers have been identified, but as of yet none of these have supplanted AFP, hCG, or LDH.

\section{Placental alkaline phosphatase}

Placental-like alkaline phosphatase (PLAP) is a membranebound protein phosphotyrosine phosphatase normally expressed in fetal germ cells and infants. It was originally demonstrated in seminoma tissue by Wahren et al..$^{30}$ In one small series it was shown to be specific for seminoma and also decreased in response to therapy. ${ }^{31}$ However, PLAP has a low sensitivity for GCT, and serum levels are frequently elevated in smokers in the absence of testicular cancers, limiting its usefulness as a GCT marker. ${ }^{32}$

\section{Neuron-specific enolase}

Neuron-specific enolase (NSE) has been used previously as a marker for neuroendocrine tumors. ${ }^{33}$ NSE is present in seminoma cells and has been proposed as a potential novel marker for this disease. ${ }^{34-36}$ Interestingly, NSE is less commonly elevated among patients with stage I seminoma, so it may be most useful in metastatic disease. For instance, using an upper cut-off of $8 \mathrm{ng} / \mathrm{mL}$, one small case-control study showed that only one-third of patients with stage I seminoma had elevated NSE. ${ }^{37}$ Using a cut-off of $13 \mathrm{ng} / \mathrm{mL}$, another series found that $15 \%$ (eight of 53) of stage I seminoma patients had elevated NSE. Furthermore, three of these eight (38\%) stage I patients had persistent NSE elevations after orchiectomy. ${ }^{38}$ Another small case series showed that among seven patients with elevated pretreatment NSE, chemotherapy resulted in normalization of NSE serum levels. ${ }^{34}$ More importantly, NSE is at times elevated in seminoma patients with normal hCG and LDH levels, making it an intriguing alternative tumor marker to aid in the diagnosis and surveillance of seminoma. ${ }^{37}$ Unfortunately, NSE is not specific for seminoma; patients with NSGCTs have been shown to have elevated NSE. One series showed that $21 \%$ of patients with localized NSGCT and $50 \%$ of patients with metastatic NSGCTs had elevated NSE. ${ }^{38}$ These preliminary findings require further investigation before the utility of NSE as a testis tumor marker can be confirmed. Currently, NSE is used only experimentally and has not yet gained traction as a marker for GCTs.

\section{TRA- I-60}

TRA-1-60 is a cell surface antigen expressed by embryonal carcinoma and carcinoma in situ of the testis. ${ }^{39}$ Elevated serum levels of this marker have been noted in patients with disseminated NSGCTs. ${ }^{40}$ Using a two-step immunoassay with a monoclonal antibody specific for TRA-1-60, Marrink et a $\mathrm{l}^{40}$ found that 32 of 42 (76\%) NSGCT patients had elevated serum TRA-1-60 levels. Furthermore, in this series there were no patients with seminoma who had elevated TRA-1-60 levels. Among patients with disseminated disease, chemotherapy significantly lowered serum TRA-1-60 levels, but these levels remained elevated in $15 \%-30 \%$ of patients without evidence of persistent disease. ${ }^{41}$ Others have reported elevated TRA-1-60 levels in patients with disseminated seminoma ${ }^{41}$ The findings merit further investigation, but TRA-1-60's lack of specificity likely limits its usefulness as a marker for testicular cancer. 


\section{Lectin reactive AFP (AFP-L3 and AFP-L2+L3)}

Elevated AFP levels have been associated with both benign and malignant liver disease. There are many subtypes of AFP; lectin-reactive AFP (eg, AFP-L3) is AFP bound to a sugar group that binds a specific lectin. ${ }^{42}$ Lectins are proteins with a particular affinity for specific sugar moieties. ${ }^{43}$ AFP-L3 was found to have excellent sensitivity and specificity for patients with hepatic malignancies. Specifically, patients with elevated AFP in the setting of malignant disease have a higher proportion of AFP-L3 in the serum. ${ }^{44}$ Kamoto et $\mathrm{al}^{45}$ evaluated lectin-reactive AFP in men with NSGCTs. Among 25 men with NSGCTs and elevated AFP, the proportion of AFP-L3 exceeded $50 \%$ in 24 cases, suggesting that the proportion of AFP-L3 may be useful in discriminating between benign conditions versus NSGCTs. A more recent study showed that patients with NSGCTs had significantly elevated levels of AFP-L2+L3 ${ }^{46}$ Interestingly, two patients in this series had persistently elevated AFP-L2+L3 levels in the setting of normal AFP after treatment. Both subsequently went on to recur, heralded by elevated AFP levels, suggesting that this marker may be useful to identify patients who fail primary therapy earlier in their treatment course. ${ }^{46}$ Further investigations are needed to confirm the usefulness of AFP-L3 and AFPL2+L3 in patients with NSGCTs.

\section{Cell-free circulating DNA}

A more promising novel GCT marker is cell-free circulating DNA. Cell-free circulating DNA is present in the serum, not contained within cells or their nuclei. Cell-free circulating DNA has been identified in a variety of malignancies, including prostate, bladder, and lung cancers. ${ }^{46-49}$ One study evaluated cell-free DNA in 74 patients with GCTs and found that levels were significantly elevated in GCT patients compared with controls. In addition, patients with advanced disease (ie, stage III) had significantly greater titers of cell-free DNA compared with those with stage I or II disease. Elevated levels were found in patients with seminoma and NSGCTs. Using a threshold of $2.56 \mathrm{ng} / \mathrm{mL}$, cell-free DNA had an $88 \%$ sensitivity and $97 \%$ specificity for men with GCTs. ${ }^{47}$ Despite these promising findings, lack of standardization of the test, limited availability of the assay, and the small sample size tested preclude any broad application of cell-free circulating DNA in testis cancer at this time.

\section{Conclusion}

Testicular tumor markers (hCG, AFP, and LDH) are instrumental in the diagnosis, staging, and surveillance of seminomas and NSGCTs. The degree of elevations of tumor markers correlates to disease burden and provides important prognostic information. The rate of decline of these markers and whether or not they normalize following treatment predict the ultimate response to therapy. Tumor markers should be monitored as a component of the standard surveillance protocol following treatment of testicular cancer regardless of the presence of initial marker elevation or tumor histopathology. Current tumor markers cannot replace a tissue diagnosis in treating GCTs, however, as they lack sensitivity and specificity; AFP, hCG, and LDH can be elevated in benign conditions. There are a number of novel and potentially clinically useful alternative GCT markers. These include NSE, TRA-1-60, PLAP, lectin-reactive AFP, and cell-free circulating DNA. These markers are still investigational and require further research to establish their role in testicular cancer.

\section{Disclosure}

The authors report no conflicts of interest in this work.

\section{References}

1. Biggs ML, Schwartz SM. Cancer of the testis. In: Ries LAG, Young JL, Keel GE, Eisner MP, Lin YD, Horner M-J, editors. SEER survival monograph: cancer survival among adults: US SEER Program, 1988-2001, patient and tumor characteristics. Bethesda, MD: National Cancer Institute; 2007:165-170.

2. Manecksha RP, Fitzpatrick JM. Epidemiology of testicular cancer BJU Int. 2009;104(9B):1329-1333.

3. American Cancer Society. Cancer Facts and Figures 2011. Atlanta, GA: American Cancer Society; 2011

4. Richie J, Steele G. Neoplasms of the testis. In: Wein AJ, Kavoussi LR, Novick AC, Partin AW, editors. Campbell-Walsh Urology. Philadelphia, PA: Saunders; 2007:907-908.

5. Gilbert SM, Daignault S, Weizer AZ, Wei JT, Hollenbeck BK. The use of tumor markers in testis cancer in the United States: a potential quality issue. Urol Oncol. 2008;26(2):153-157.

6. Germa-Lluch JR, Garcia del Muro X, Maroto P, et al. Clinical pattern and therapeutic results achieved in 1490 patients with germ cell tumours of the testis: the experience of the Spanish Germ-Cell Cancer Group (GG). Eur Urol. 2002;42(6):553-563.

7. Bosl GJ, Motzer RJ. Testicular germ-cell cancer. N Eng J Med. 1997; 377:242-254.

8. Lempiainen A, Stenman UH, Blomqvist C, Hotakainen K. Free betasubunit of human chorionic gonadotropin in serum diagnostically sensitive marker of a seminomatous testicular cancer. Clin Chem 2008;54:1840-1843.

9. Gilligan TD, Seidenfeld J, Basch EM, et al. American Society of Clinical Oncology clinical practice guideline on uses of serum tumor markers in adult males with germ cell tumors. J Clin Oncol. 2010;28(20):3388-3404.

10. Carl J, Christensen TB, con der Maase H. Cisplatinum dose dependent response in germ cell cancer evaluated by tumour marker modeling. Acta Oncol. 1992;31(7):749-753.

11. Boyle LE, Samuels M. Serum LDH activity and isoenxyme patterns in non-seminomatous germinal (NCG) testis tumors. Proc Am Soc Clin Oncol. 1977;18:278.

12. Skinner DG, Scardino PT. Relevance of biochemical tumor markers and lymphadenectomy in management of nonseminomatous testis tumors: current perspective. J Urol. 1980;123:378-382. 
13. International Germ Cell Cancer Collaborative Group. International germ cell consensus classification: a prognostic factor based staging system for metastatic germ cell cancers. J Clin Oncol. 1997;15(2): 594-603.

14. Bosl GJ, Geller NL, Cirrincione C, et al. Multivariate analysis of prognostic variables in patients with metastatic testicular cancer. Cancer Res. 1983;43:3403-3407.

15. Toner GC, Geller NL, Tan C, Nisselbaum J, Bosi GJ. Serum tumor marker half-life during chemotherapy allows early prediction of complete response and survivial in nonseminomatous germ cell tumors. Cancer Res. 1990;50:5904-5910.

16. Olafsson SE, Tandstad T, Jerkeman M, et al. Population-based study of treatment guided by tumor marker decline in patients with metastatic nonseminomatous germ cell tumor: a report from the Swedish-Norwegian Testicular Cancer Group. J Clin Oncol. 2011;29(15):2032-2039.

17. De Santis M, Becherer A, Bokemeyer C, et al. 2-18-fluoro-deoxy-Dglucose positron emission tomography is a reliable predictor for viable tumor in postchemotherapy seminoma: an update of the prospective multicentric SEMPET trial. J Clin Oncol. 2004;22(6):1035-1039.

18. Rathmell AJ, Brand IR, Carey BM, Jones WG. Early detection of relapse after treatment for metastatic germ cell tumour of the testis: An exercise in medical audit. Clin Oncol. 1993;5(1):34-38.

19. Trigo JM, Tabernero JM, Paz-Ares L, et al. Tumor markers at the time of recurrence in patients with germ cell tumors. Cancer. 2000; 88(1):162-168.

20. Fossa SD, Stenning SP, Gerl A, et al. Prognostic factors in patients progressing after cisplatin-based chemotherapy for malignant non-seminomatous germ cell tumours. Br J Cancer. 1999;80(9):1392-1399.

21. Mego M, Rejlekova K, Reckova M, et al. Kinetics of tumor marker decline as an independent prognostic factor in patients with relapsed metastatic germ-cell tumors. Neoplasma. 2009;56(5):398-403.

22. Baniel J, Foster RS, Gonin R, Messemer JE, Donohue JP, Einhorn LH. Late relapse of testicular cancer. J Clinc Oncol. 1995;13:1170-1176.

23. Michael H, Lucia J, Foster R, Ulbright T. The pathology of late recurrence of testicular germ cell tumors. Am J Surg Pathol. 2000;24(2): 257-273.

24. Shahidi M, Norman AR, Dearnaley DP, Nicholls J, Horwich A, Huddart RA. Late recurrence in 1263 men with testicular germ cell tumors. Multivariate analysis of risk factors and implications for management. Cancer. 2002;95(3):520-530.

25. Gerl A, Clemm C, Schmeller N, Hentrich M, Lamerz R, Wilmanns. Later relapse of germ cell tumors after cisplatin-based chemotherapy. Ann Oncol. 1997;8(1):41-47.

26. Braunstein GD, Thompson R, Gross S, Soares JR. Marijuana use does not spuriously elevate serum human chorionic gonadotropin levels. Urology. 1985;25(6):605-606.

27. Trojan A, Joller-jemelka H, Stahel RA, Jacky E, Hersberger M. False-positive human serum chorionic gonadotropin in a patient with a history of germ cell cancer. Oncology. 2004;66(4):336.

28. Schefer H, Mattmann S, Joss RA. Hereditary persistence of alphafetoprotein. Case report and review of the literature. Ann Oncol. 1998; 9(6):667-672

29. Fossa SD, Qvist H, Stenwig AE, Lien HH, Ous S, Giercksky KE. Is postchemotherapy retroperitoneal surgery necessary in patients with nonseminomatous testicular cancer and minimal residual tumor masses? J Clin Oncol. 1992;10(4):569-573.

Open Access Journal of Urology

\section{Publish your work in this journal}

The Open Access Journal of Urology is an international, peer-reviewed, open access journal publishing original research, reports, editorials, reviews and commentaries on all aspects of adult and pediatric urology in the clinic and laboratory including the following topics: Pathology, pathophysiology of urological disease; Investigation and treatment of
30. Wahren B, Holmgren PA, Stigbrand T. Placental alkaline phosphatase, alphafetoprotein and carcinoembryonic antigen in testicular tumors, tissue typing by means of cytologic smears. Int $J$ Cancer. 1979;24(6):749-753.

31. Lange PH, Millan JL, Stigbrand T, Vessella RL, Ruoslahti E, Fishman WH. Placental alkaline phosphatase as a tumor marker for seminoma. Cancer Res. 1982;42:3244-3247.

32. De Broe ME, Pollet DE. Multicenter evaluation of human placental alkaline phosphatase as a possible tumor-associated antigen in serum. Clin Chem. 1988;34(10):1995-1999.

33. Tapia FJ, Barbosa AJA, Marangos PJ, et al. Neuron-specific enolase is produced by neuroendocrine tumors. Lancet. 1981;317:808-811.

34. Kuzmits R, Schernthaner G, Krisch K. Serum neuron-specific enolase: a marker for response to therapy in seminoma. Cancer. 1987; 60(5):1017-1021.

35. Niehans GA, Manivel C, Copland GT, Scheithauer BW, Wick MR. Immunohistochemisty of germ cell and trophoblastic neoplasms. Cancer. 1987;62(6):1113-1123.

36. Takashi M, Haimoto H, Nagal T, Koshikawa T, Kato K. Enolase isozymes in seminoma. Urol Res. 1990;18(3):175-180.

37. Fossa SD, Klepp O, Paus E. Neuron specific enolase: a serum tumor marker in seminoma? Br J Cancer. 1992;65(2):297-299.

38. Tandstad T, Klepp O. Neuron-specific enolase in testicular cancer. Acta Oncol. 2003;42(3):202-206.

39. Andrews PW, Banting G, Damjanov I, Arnaud D, Avner P. Three monoclonal antibodies defining distinct differentiation associated with different high molecular weight polypeptides on the surface of human embryonal carcinoma cells. Hybridoma. 1984;3(4):347-361.

40. Marrink J, Andrews PW, Van Brummen PJ, De Jong HJ, et al. TRA-1-60: a new serum marker in patients with germ-cell tumors. Int J Cancer. 1991;49(3):368-372.

41. Lajer H, Daugaard G, Andersson A, Skakkebaek NE. Clinical use of serum TRA-1-60 as tumor marker in patients with germ cell cancer. Int $J$ Cancer. 2002;100(2):244-246.

42. Breborowicz J. Microheterogeneity of human alphafetoprotein. Tumour Biol. 1988;9(1):3-14.

43. Barondes SH. Lectins: their multiple endogenous cellular functions. Annu Rev Biochem. 1981;50:207-231.

44. Taketa K, Endo Y, Sekiya C, et al. A collaborative study for the evaluation of lectin-reactive alpha-fetoprotein in early detection of hepatocellular carcinoma. Cancer Res. 1993;53:5419-5423.

45. Kamoto T, Satomura S, Yoshiki T, Okada Y, et al. Lectin-reactive a-fetoprotein (AFP-L3\%) curability and prediction of clinical course after treatment of non-seminomatous germ-cell tumors. Jpn J Clin Oncol. 2002;32(11):472-476.

46. Kawai K, Kojima T, Miyanaga N, et al. Lectin-reactive alphafetoprotein as a marker for testicular tumor activity. Int J Urol. 2005; 12(3):284-289.

47. Ellinger J, Muller SC, Stadler TC, Jung A, von Ruecker A, Bastian PJ. The role of cell-free circulating DNA in the diagnosis and prognosis of prostate cancer. Urol Oncol. 2011;29(2):124-129.

48. Ellinger J, Bastian PJ, Ellinger N, et al. Apoptotic DNA fragments in serum of patients with muscle invasive bladder cancer: a prognostic entity. Cancer Lett. 2008;264(2):274-280.

49. Sozzi G, Conte D, Mariani L, et al. Analysis of circulating tumor DNA in plasma at diagnosis and during follow-up of lung cancer patients. Cancer Res. 2001;61:4675-4678.

urological disease; Pharmacology of drugs used for the treatment of urological disease. The manuscript management system is completely online and includes a very quick and fair peer-review system, which is all easy to use. Visit http://www.dovepress.com/testimonials.php to read real quotes from published authors. 